\title{
A smart place to work? Big data systems, labour, control and modern retail stores
}

\author{
Leighton Evans (1) and Rob Kitchin
}

\begin{abstract}
The modern retail store is a complex coded assemblage and data-intensive environment, its operations and management mediated by a number of interlinked big data systems. This paper draws on an ethnography of a retail store in Ireland to examine how these systems modulate the functioning of the store and working practices of employees. It was found that retail work involves a continual movement between a governance regime of control reliant on big data systems which seek to regulate and harnesses formal labour and automation into enterprise planning, and a disciplinary regime that deals with the symbolic, interactive labour that workers perform and act as a reserve mode of governmentality if control fails. This continual movement is caused by new systems of control being open to vertical and horizontal fissures. While retail functions as a coded assemblage of control, systems are too brittle to sustain the governmentality desired.
\end{abstract}

Keywords: retail, control, discipline, code/space, labour, big data, automation.

\section{Introduction}

There used to be more chance for contact and more time with customers. Now, do people care enough?

(Customer Services Operative).

The retail industry has to balance good customer service and soft labour skills with efficiency, maximising revenue and formal labour. In large retail stores, interaction with customers and the skills of selling sit parallel to highly automated stock control processes, supply chain integration and automated resource planning. In addition, the staff in such environments have their labour translated into data through a variety of techniques. For workers who have spent a long time in retail, such as the customer services operative quoted above (13 years), the increasing use of systems of control that utilise big data stand in stark contrast with regimes that they started their careers with that used less intense, more disciplinary forms of governance. This paper explores the changing conditions of work and workplaces in the age of big data in the retail sector. The introduction of new computational systems into retail operations

Leighton Evans (L.Evans@swansea.ac.uk), is a Senior Lecturer in Media Theory at Swansea University, Wales. He is a Media Theorist with research interests in digital culture, social media, phenomenology, virtual reality and the mediation of work by digital media.

Rob Kitchin, is a Professor and ERC Advanced Investigator at the National Institute of Regional and Spatial Analysis, Maynooth University, Ireland. Rob's research interests are in software, big data, smart cities, the internet and cyberspace and data infrastructures and practices. 
that generate, process and work upon big data mean that all elements of the work environment and forms of labour have become highly mediated by software collectively forming a coded assemblage (Kitchin and Dodge, 2011) and also deeply surveilled (Newsome et al., 2013).

The aim of our research was to understand how such computational systems mediate and transform the nature of labour and workplace governmentality and the consequences with regards to staff work practices and conditions. The paper first outlines the extent to which big data systems have become pervasive in the retail sector. We then chart how new big data systems attempt to shift workplace governmentality from a regime of discipline to a regime of control and the horizontal and vertical fissures undermining such a shift. Next we explore the governmentality operating on a daily basis within a large retail store, drawing on observations from an ethnographic study conducted in Ireland. Specifically, the empirical study sought to address three questions: (1) what are the discernible changes in modes of governance in the modern retail environment due to big data systems? (2) what factors are responsible for disruptions to governance? (3) what are the effects of these changes on workers?

\section{The modern retail store as a big-data environment}

Modern retail is a data intensive business reliant on extensive information management systems such as Enterprise Resource Planning (ERP), Supply Chain Management (SCM) and Customer Relationship Management (CRM) (Chopra and Meindl, 2012; Dery et al., 2006). These systems aim to facilitate greater coordination and control within a retail organisation, and with suppliers and customers, using big data - that is, vast quantities of fine-grained (at the level of individual products, staff, customers), exhaustive and quickly transitioning data produced through the everyday, routine interactions with the various systems used to conduct business (Kitchin, 2014). Such big data systems are seen as vital for producing extended coordination and improved decision-making and operational intelligence, creating organisational efficiencies, innovating new services and business models, and improving customer experience, thus leveraging additional profit and competitive advantage while reducing risks, costs and operational losses. In addition, they are marketed as enabling retailers to be nimbler, opportune, flexible, innovative and smart in how they are organised and operate (Manyika et al., 2011). These big data systems are having profound effects on the nature of retail labour.

These systems change labour practices in three respects. First, they change the forms of work, with tasks mediated by digital devices and practices. Second, they replace some work tasks with automation or semi-automation (such as self-service checkout tills, or automatically computed delivery routes). Third, they change the nature of governmentality and the way in which the work of staff is managed, overseen and regulated. With respect to the second and third points, technological infrastructures will create less human labour, but not in the way Keynes (1936) envisaged, wherein a planned form of technological unemployment would exist (Floridi, 2014; Danaher, 2016a). Instead, a fear of idleness, a failure to decouple employment and income, and the positioning of the Protestant work ethic as the central ethical position of our time have meant there is a dependency on working with and under the technological conditions that may have released humans from such labour. As such, the technological conditions of modern labour have created a subject caught in precarious employment situations, such as retail work, that is always available for work, and cannot get enough work, but also must be held in reserve for work at any time (Correll et al., 2014).

Within these conditions, an epistocracy emerges (Estlund, 1993) that constitutes a particular kind of governance based on computer-programmed algorithms (Danaher, 2016a). Algorithms are used to collect, collate and organise data on which decisions in the workplace are made. Algorithms both assist in how data are structured, processed and communicated through relevant governance systems, and structure and constrain how workers interact with systems, one another, the data, and the broader community that is affected by such systems. Here, data mediated through number-crunching 
algorithms and machine learning are understood as more reliable and trustworthy (and aligned with key performance indicators) than the impressions of mere employees (Fuller and Goffey, 2012). Aneesh (2006) refers to this as an algocracy, an organisational system distinct from the market or other organisations which overlaps with other algocracies and interacts with them - for example, a 'human-out-of-the-loop' system, such as predictive systems like stock control in supermarkets. The effect of such systems and modes of governance in a retail store is to actively divorce labour from the reasons for doing the task, as allocated by opaque systems (Danaher, 2016b). Morozov (2013a,b) refers to this as a 'web of invisible barbed wire', where systems of control constrain and construct work without visibility and without requisite knowledge in labour, or labour organisations able to scrutinise these structures (Andrejevic, 2014; Mittelstadt and Floridi, 2016). The result is a lack of satisfaction in work as the worker is divorced from the motivation and reasoning for work (Danaher, 2016a). The effect of such a working environment is precarious employment where workers experience degradation with a lack of political intervention in such a process as the issues are poorly understood (Smith, 2012).

In a historical context, the use of data in the workplace is part of the ongoing project of scientific management of work (Gregg, 2016). Like in the disciplinary techniques of Gilbreth and Gilbreth (1917), Roethlisberger and Dickson (1939), and Taylor (1903) in general, slow motion capture techniques are reproduced in the big data age, but with a commensurate increase in speed and a lack of direct intrusion; with an increase in overall intrusion, such as through work outside of the workplace in the form of expected use of email and other applications. Technological innovations in the workplace - such as sales-based ordering or inventory management prevalent in retail environments - are therefore used to determine the speed and character of labour (Gregg, 2016). This is materialised in workplace surveillance that blurs the boundary of public and private spheres (Dash, 2014). The use of technology to rid organisations of 'time theft' (Ehrenreich, 2010: 29) through surveillance has led to a situation where 75 per cent of all companies monitor usage of the internet at work (Ball, 2010). Further to this, the routine use of tracking technologies on employees, such as Amazon's monitoring of employee movement in warehouses (McClelland, 2012), and the firing of employees for a lack of 'hustle' (Head, 2014) are more severe extensions of the same observational logic. Following from Deleuze (1992), in a post-Fordist environment, such as the big data-infused retail store, power is mobile and mobilised by technology. The aim of this technologically-infused surveillant workplace is efficiency, a situation that Rossiter (2014: 53) views as a nightmare combination of enterprise resource planning (ERP) and key performance indicators (KPIs) used to modulate the experience of the work world. The tracking of employees becomes an informatised sovereignty (Rossiter, 2014: 68) where 'code is king' and data are used to maximise the effectiveness of worker bodies. With no delay between movement and data collection and processing, code means that there is always, and only, work.

\section{Discipline and control of labour in a coded assemblage}

The effect of the presence of big data systems in the workplace that monitor and assess labour performance continually is to create a new kind of power that sits in contrast with previous modes of labour governmentality. Big data systems greatly intensify the extent and frequency of monitoring of labour and shifts the governmental logic from surveillance and discipline to capture and control (Deleuze, 1992; Agre, 1994) through the use of systems that are distributed, ubiquitous and increasingly automated, automatic and autonomous in nature (Dodge and Kitchin, 2007). That is, there is a shift from Foucault's (1979) notion of disciplinary technologies to Deleuze's (1992) concept of technologies of control.

Foucault's notion of discipline as a mode of power positions discipline as a 'machine' that works on a societal scale (Foucault, 1979). The four mechanisms of this 'machine' are: individuals being distributed in space; activity in space being 
regulated; the organisation of geneses - a series of techniques being used to organise the training of individuals; and the composition of forces where the organisation of each technique is to produce an end product of an individual subject (Savat, 2012: 16). These four mechanisms operate as an assemblage or 'machine' through three instruments: hierarchical observation; normalising of judgement; and the examination (through scrutiny of status or data). The success of any disciplinary mechanism is dependent upon these instruments. Any change in the apparatus (such as through new data techniques or the use of databases) acts to amplify or change the nature of discipline. As such, in a data society discipline is vastly extended across the lifeworld. For Foucault, this produced power distributes individuals in a permanent and continuous field in which they self-discipline, actively managing their behaviour to comply with expectations for fear of being caught transgressing and experiencing sanctions (Foucault, 1979).

Importantly, the shift to big data systems seeks to change the mode of governmentality to control. Here, employees become subject to constant modulation through their capture in systems that shape their behaviour explicitly or implicitly nudge it, rather than being (self) disciplined (Savat, 2012). For example, the work of checkout operatives was disciplined through the gaze of the supervisor and CCTV monitoring of work rate. Now, the mode of work - the scanning of items - becomes the mechanism of capturing and regulating behaviour. Here, work is modulated by checkout till and the act of scanning becomes a site of administration (Kitchin and Dodge, 2011). Big data systems change the nature of observation (through surveillance) from a model where an observer is needed to one where observation can be distant and performed by software; behaviour is no longer adjusted in case a manager is present as the 'manager' is always present. Here, pattern recognition of the kind deployed in everyday performance management in retail environments is not panoptical, as the panopticon requires awareness by the subject that they are being watched, subjects being aware of the model towards which they have to adjust their behaviour, subjects that care about being observed, and a sense of gratification derived from following the disciplinary regime (Savat, 2012: 23).

Modulation uses different mechanisms (e.g. recognition of patterns; anticipation of activity; organisation of antitheses; and programming of code) and instruments (e.g. simulation; sorting; sampling) in its operation as a mode of power. Whereas disciplinary machines operate to make the invisible mechanisms of control visible, modulation has no need to do this as it always acts in a non-overt way without the need for an explicit gaze. The effect is that the subject produced by this form of observation is akin to Deleuze's objectile - not a subject itself, but a construct of patterns of code that emerge from activity in the digitally-infused world. Therefore, modulation does not 'see' individuals and individuals only fleetingly emerge from the flux of code and patterns, if at all (Savat, 2012: 56). This produces a dissipation of the individual and therefore a destruction of any care for the individual (Stiegler, 2010). This work world, where one is held in a state of continual anticipation, is one where the worker is always in a state of angst as the modulatory machine is always aware of the worker. In other words, governmentality is no longer solely about subjectification (moulding subjects and restricting action) but about control (modulating affects, desires and opinions, and inducing action within prescribed comportments) (Deleuze, 1995; Braun, 2014).

Within the context of retail, workers become continually monitored and modulated across the entire range of work through an amalgam of interlinked systems and overlapping calculative regimes designed to produce a certain kind of worker and work. While techniques of control in the modern retail store seek to be all-encompassing they do not completely eradicate discipline because they are open to vertical and horizontal disruption. The vertical fissures arise because not all big data systems employed are integrated across the organisation, being siloed to some degree, and they are open to rupture and failure. Systems are introduced at different times, utilise different technologies and standards, and are sometimes not fit for purpose, performing sub-optimally. In addition, the data in systems can be flawed or out-of-date. When 
control systems fail, former disciplinary systems have to fill the gap (see Newsome et al., 2013: 7-8).

The horizontal fissures emerge because all forms of retail labour are not easily captured and controlled. Service labour-intensive workplaces paradoxically prioritise formal work over interactive and emotional labour (Sallaz, 2010). Given that working in a retail environment involves customer-facing and customer service roles, this prioritisation of goal and target-oriented activity over softer, customer focussed interpersonal interactions is problematic. Retail work also includes a series of one-to-one interactions that significantly influence customer satisfaction (Leidner, 1993). While management seeks to influence customer feelings through the close management of employees' emotional displays (Hochschild, 1985), there is a significant barrier to mobilising these kinds of symbolic labour in a big data regime (Sallaz, 2010). Competition demands high levels of service, but the operational mechanisms and key performance indicators (KPIs) used in big data environments are not designed to encompass this symbolic labour. While workers engage in interactive and emotional labour continually in their roles, their performance is only assessed on formal labour in the data infrastructure of the retail store. As such, disciplinary techniques are still employed in retail environments to govern symbolic labour, in continual oscillation with control techniques that govern formal work and monitor performance. These different modes of power in the workplace impact upon the experience of work for the labourer and create a work world that is paradoxical, contradictory and confusing while still being quantified and tightly regulated. The worker becomes an interface (Lazzarato, 1996) between the different functions and levels of hierarchy in the workplace, continually moving between disciplinary and control regimes and embodying these in their labour practices - and therefore always being monitored by different techniques, for different (or nonexistent) reward and punishment mechanisms.

\section{Case study: a retail store in Ireland}

It is the changing nature of labour and governmentality in retail industry, the movement between disciplinary and control regimes, and the vertical and horizontal fissures at play that we are centrally concerned with examining through our case study, highlighting the precarious and provisional state of play due to the rapid adoption of big data systems. The empirical, on-site fieldwork took place over a nine-week period between September and November 2015 at a large retail store operating in Ireland. The store is part of a large, multi-national chain in the Republic of Ireland, with typically 80-110 people working in the fieldwork store per shift across all departments, and a skeleton crew of 15-25 working at night during the closing hours of the store (variations according to seasonal demand). The research was conducted within the parameters of health, safety, training and University ethics approval and was subject to a non-disclosure agreement with the chain.

20 individuals were interviewed in 15 separate interviews, complemented with a set of 10 periods of observation of workers at work, and observant participation through work placement. The researcher was placed for one week in each of the following departments, conducting interviews, learning and performing tasks, and observing working practices: online ordering and delivery; customer services; electrical products; stock control; price integrity; compliance; and front end (checkouts). The interviews took place with two delivery drivers working in the home delivery department; two team leaders, the driver coordinator and the manager of the home delivery department; three checkout operators; the checkout team leader; the stock control manager and a stock control operative; two customer service operatives; the in-store optician; two phone shop operatives; the compliance manager; the store manager, and the deputy manager. Observation periods in each department typically consisting of being partnered with a worker in the store and observing their work for a period of one hour. There was some variation in this observation period; two observations in the customer service department lasted for four hours across a typical shift for both 
the workers, while the observation of a driver on a drive took five hours along their entire route. Within the online ordering and delivery department, the researcher was trained to use a Personal Digital Assistant device (PDA) and was allowed to go on a 'run' (a supervised pick of items for an online order) as well as observing several runs with team leaders.

Interviews were conducted following observation periods or after meetings with senior staff. When possible, interviews were recorded and transcribed, but as some had to take place in noisy environments detailed notes were taken and expanded upon in detailed interview records. Observations were recorded by taking field notes which were collated and corroborated with participants following the observation. Following macro-analysis of the data, a thematic analysis of the material derived from the critical discourse analysis approach (Fairclough, 1995) identified three key, repeated and significant horizontal and vertical fissures that reoccurred across interviews and observations and significantly commented upon the central research questions.

\section{Vertical and horizontal fissures in control}

The store management consistently identified the key challenges for the store as growing sales and planning the trade deals for the week. Managers primarily use the email system, work plan, Sales Based Ordering (SBO), and store reports derived from these systems to provide, compile and communicate data for the running of the store. Major issues identified by store workers were 'no clear link between [company] vision and operations in store', 'honest communications' between managers and staff, 'clearer targets from line managers', and 'health and wellbeing' (including wages and hours). The presence and functioning of a variety of data-intensive systems to produce a data intensive environment contributes to these issues. In particular, the research found three major vertical and horizontal fissures:

- People work 'for the data', where tasks become data-fulfilment and data-satisfying rather than people-, task- or customer-focussed. This is particularly problematic in roles that are distanced from direct customer interaction (horizontal).

- Non-coded activities and symbolic labour (such as strong customer relationships or service), while praised, are not part of formal evaluation or appraisal of staff because they are not easily captured data (horizontal).

- Systemic system failure (where systems do not work properly or are subject to disruption) and equipment issues (old, absent or malfunctioning media) form major operational concerns and are a source of frustration for those working in the store or on particular tasks (vertical).

\section{Working for data}

An example of work being directed by data - and therefore the totalisation of formal work, or a regime of control - is the 'picking' operation for home deliveries that are scheduled through the company's online ordering portal. The picking PDA device (reliant on a $3 \mathrm{G}$ signal rather than store $\mathrm{Wi}-\mathrm{Fi}$ ) directs the activities of the picker and how a 'pick' (the route around the store and order of collection of items) is undertaken. The interaction with coded data is intense; the picker must scan their personal ID barcode with the PDA to activate themselves on the device; the picker scans each individual order (up to 6) on their trolley; this generates an order of the pick based on items location in the store; the picker must then scan the begin/end barcode (located next to the doors of the deliveries area) to start their pick. The level of automation in directing the task makes this a highly software and data dependent activity. 
The mapping of the store is critical to picking, and the accuracy of the mapping becomes a function in the efficiency and accuracy of each worker. Each order in a run has an exact location: [aisle number] [left or right of aisle] [mod] [shelf number] [position on shelf]. The mapping of items in the store by stock control provides this detailed information, and the sequence on the PDA reflects this data. Once at the item, the item barcode is scanned using the PDA and if the correct item has been picked (a short text description of the item is displayed on the PDA LED screen) then the PDA displays a tick. The picker can then place the item into the correct customer box and scans a barcode at the side of each crate to end that item and move on to the next item. In theory this system is ideal; however sometimes the system 'guesses' where an item is (i.e. relies on out-of-date location data that has not been updated). This data lag can delay performance and eventually delay the departure of drivers with orders for customers. This is both a data issue and an interoperability issue, with the stock control system (and changes in stock control) not being reflected in the online order fulfilment system. The mapping of the store also causes major issues, especially on Wednesdays when the ends of aisle displays are changed for offers as old items can often still be mapped in the wrong places.

The nature of the task and the extent to which the task is dictated by the PDA and data fulfilment aspect means that this role is one which is (more than any other in store) distanced from the customer. In effect, the use of the PDA to navigate the store creates a 'warehousing' effect wherein the picking team encounters the store differently to colleagues. While there are some interactions with customers and with colleagues, the primary interaction in work is the PDA and not with the customer or the store 'as a store'. This formal labour is a clear instance of a regime of control, with worker movement highly modulated - that is, planned, controlled, scheduled and timed - for maximum efficiency and minimal (ideally no) symbolic labour (as detailed in the context of civil service work by Carter et al., 2011: 90). Performance is totally objectified and informationalised, and performance review is derived from systems rather than direct observation by managers. However, staff dissatisfaction with the work derives from the malfunctioning of systems, with little reflection on Morozov (2013a,b) 'web of barbed wire' that exerts control.

\section{Non-coded activities and symbolic labour}

There are a number of work tasks that are not mediated by coded systems or captured within employee performance metrics. Customer service is one such activity and performing the role can seriously affect the metrics of those tasks that are measured. For example, in the picker role, individual run performance is not assessed, rather overall average performance is a part of appraisal. However, as there are customers in the store at the time of the pick, pickers must if asked break off from their duties to assist customers, which in turn affects pick rates (with KPIs of 80-120 items per hour, depending on demand). Customer service would need to be recorded - through pausing the pick or signing off for the time needed to assist the customer (recording the activity in some way) - if it is to be rewarded, but this is not the case. Any demand for a switch to symbolic labour is, however, considered critical by management, and cannot be ignored. Here, the two regimes of power in the store clash most clearly; control requires following the coded system, discipline requires ignoring the system and falling into a customer service role where the reward mechanisms are fuzzy, undefined and conventional rather than data-driven.

The front end (checkouts) also includes activity that is not coded, but which is vital to the customer service element of the store. The team leader monitors checkout performance reports that give data on sales and customers, time taken by each operator, numbers of interventions, sales totals, and issues with pricing. These are measured against KPIs for efficiency and speed of scanning and form part of the appraisal of operators. However, interactive labour is critical in this role and is not assessed - only formal work is incorporated into the system of appraisal, unless a worker's emotional 
or interactive labour is substantially deficient through non-coded observation and customer complaints. A different but related issue emerges in customer services. This is a very busy role, with a continual switching of tasks, interfaces, and system interactions. Customer and colleague communication is critical, and must be continued along with the execution of other tasks. There are five systems at play at any time: post (bills; postal items; currency); lottery; stock control (returns); checkout; and telephones/staff communications. Because of this overload of systems and equipment, many phone calls cannot be answered as the role is too demanding.

Similarly, the self-serve point-of-sale (PoS) units are designed for the customer to do the 'work', although intervention from an operator was needed in one in every five customer interactions in the period observed. The operator of the self-scan area stands next to the monitor that displays information on each of the checkouts in the area. This screen has a touchscreen interface with the screen divided into six areas (one for each checkout). Checkouts that are out-of-order are indicated in red, checkouts operating correctly in green, and idle in grey. If a customer has an issue while using the checkout the display for that PoS unit turns red to alert the operator - they then restore the status of the checkout to green once the issue has been resolved. The real-time monitoring station gives feedback on items scanned, price of items and quantity of items, and keeps a running total of customers that have passed through the area in a session. While this activity can be recorded and reported upon, and despite this being a customer activity, the operator role is very manual - there are frequent interventions made and assistance given. The operator needs to be constantly vigilant for customer care, as well as attending to formal duties. The performance of this customer service role is not recorded, nor are the continual interventions to assist in self-service. The non-coded activities were seen as being, by far, the most important part of the role by the operator, yet was the least commented on when it comes to appraisal. Indeed, the role itself was summarised as a 'thankless task' by staff. Positive formal customer feedback is rare, although negative formal feedback is acted upon quickly by management and such sessions ignore data on task performance which is stored in the PoS system.

A very clear indication of this tension between systems of control and discipline was observed in the electrical department, specifically in the mobile phone area. Two key functions are sales and troubleshooting, with roughly a one-to-three division in time between these functions although the latter has no bearing on the KPIs of the department. The KPIs are narrowly based on new connections to pay-monthly tariffs, with a sales KPI target of 19 new connections per week (the store achieves 20-23 on average, but this is not evenly distributed through the year). Troubleshooting takes up most of their time, and during our observation we observed a worker writing texts for a customer and accessing and resetting an email account for another. The excellent customer service was not recorded in any way, despite it being integral to the role at it taking up the most time. Again, the symbolic labour (in this case, explicitly emotional and interactive labour intended to ease customer distress with technology) is disregarded in the regime of control being sought in the store, and only fleetingly if at all attended to in the regime of discipline. With KPIs tethered so closely to data production, analysis and provision, the regime of control appears to be a barrier to the appreciation of non-coded activity in the way that Sallaz (2010) argues.

\section{Systemic system and equipment failures}

Systemic system and equipment failures are a continual issue in the store. These situations arise because although the environment is highly data dependent, it relies in some cases on old digital technology that has limited capability and lacks interoperability with other systems. These shortcomings arise because the technology was purchased at different times, with the capabilities available at the time of purchase, with the system upgraded or patched or worked around but not replaced. The wholesale replacement of a technical system is costly and brings with it certain risks, for example 
the disruption of transferring to a new system and embedding it into existing systems and work practices. At the same time, there are also clear risks in persisting with systems with known issues. For example, members of the store management team stated that the in-store communication systems are highly problematic. Every day, the store managers begin the day by collating the data from the previous day (or week if on a Monday) into a report on the KPIs for the store manager to distribute to team managers. This is done via a WhatsApp group message that managers pick up on their mobile phones (as there are no bespoke direct communications systems). The information for these KPIs comes from a combination of reports that are derived in store from the Sales Based Ordering (SBO) system through a visualisation tool, information from the 'centre' (head office) that is emailed directly to a personal account available on one PC in the store, and information retrieved from a shared networked folder available on the limited number of PCs that is password protected. Managers must check on any figures that are missing by calling the relevant person and then sending the information to the managers to give a report on performance that is intended to structure activities on the current day. While this use of social media is innovative, it is subject to the vagaries of connection to mobile signals and Wi-Fi in the store. Moreover, despite the entire store being mapped out on an item basis through barcoding, there is no real-time tool for visualising and reporting KPI data.

With regards to the online orders fulfilment team, the routing system used to direct drivers to deliveries is a major operational and system issue. While routing systems have shown that delivery operations can be improved dramatically with the application of vehicle routing analytics technology (Toth, 2015), in this situation there was no discernible improvement in delivery. Currently, in order to monitor KPIs for time of delivery of items, punctuality and route compliance the route order cannot be altered by drivers, and if the route is not followed (unless alterations are programmed by the store following a report) then the driver is penalised in their metric. This is despite the fact that local knowledge possessed by the experienced drivers who know the locations of customers and the best routing between them would improve service and costs. In particular, issues of $\mathrm{CO}_{2}$ reduction, fuel costs and customer service are raised by the use of this system (see Wang et al., 2015). Routing issues occur because of a ' 0 km' issue, where distances between delivery points in towns or townlands are recorded as $0 \mathrm{~km}$ distance whereas the distance could be up to $10 \mathrm{~km}$, with only six minutes allocated for delivery (in line with the KPIs for delivery). As one driver commented: 'the routing sets you up to be late.' Here, the issue is the use of a system designed for the postcode address system in the UK rather than the Irish addressing system, leading to routing being haphazard and sub-optimal especially in urban centres where congestion exacerbates issues (Wygonik et al., 2015). Manual routing could be used, but then the tracking of orders and data collection would be out of sync with a system that does not allow such adjustments. Here, the regime of control has a lack of fit with task demands and the pragmatic aspects of the task, but there is no regime of discipline to replace this system. Another major issue identified was illogical scheduling and routing. The order schedule on a run we observed as a passenger went: $9-11$ am deliveries; $11-1 \mathrm{pm}$ deliveries; $10-12 \mathrm{pm}$ deliveries. The non-sequential ordering allied to the need to follow routing meant that there were inevitably delivery times that were missed. Customers had to be phoned from the van to be informed when it was apparent the delivery would be late and while this was fine with some, others could not be contacted and messages had to be left, which is far from ideal customer service.

Further, the online order system requires drivers to use a reach device that collects data on times, routes and driving performance, and feeds that information into the system to refine routing and collate driver metrics. The reach device is also used to end the run through the 'return journey' function that syncs the device with the system once docked at the store. Real-time syncing is not always possible due to persistent signal issues. Moreover, the reach devices are themselves technologically obsolete, with no Global Positioning System (GPS) capabilities, and their mode of connection to the systems in-store leading to a time lag (contributing to a bullwhip effect). This time lag means that the online order fulfilment system does not operate 
in real time; it is always contingent on drivers being in the store to synchronise the device with the in-store systems.

A particular issue for online ordering that affects punctuality with regards the picking PDA is when the 'end of shop' is not recorded due to the handset crashing, or connectivity or battery issues. If this happens, the items will be returned into the stock control system (therefore appearing to be in the store) whereas in reality they have left the store and have been delivered. PDAs crashing was a frequent occurrence, especially at busier times where demands on the limited network are high. A major issue that occurs with a crash is the need to reprint labels, which means a 'shop' has to begin again. This can potentially delay the departure of the vans.

Other issues that affect stock control include the 'trunking' of non-food items and the scheduling and auctioning of stock reduction. Trunking is when an item appears on the system as stock but is not in store due to logistical issues. As non-food items are typically dispatched from the United Kingdom and have to travel to Ireland by boat before being fulfilled there is a considerable lag between an item appearing in book stocks and physically being in the store (indeed, some items are never in store). Here, the data itself does not match with physical availability of items, which can create customer service issues - a failure of the regime of control which results in a reversion to a regime of discipline. A systemic issue in the electrical department occurs when customers are sometimes denied sales after a customer security check on the landing page of the main portal. If a fail is recorded (a score of more than 10) then the sale is not approved. This is decided by an algorithm, and the team is not given reasons for why the customer has been denied, nor do they have sufficient understanding of the potential reasons as to why they might be denied. The security team that can intervene in these events is not based in store and finish each day at $4 \mathrm{pm}$ and are closed at weekends, while the shop is open from early morning until late, Monday to Sunday - so failed orders cannot be processed at many busy periods. On 1 day, while with the electrical team, the email to the security team was down so no 'fail customers' could be passed for processing (delaying four potential sales). The automation of decisionmaking and black boxing of knowledge on these processes again result in a reversion to soft, symbolic labour that is subject to an undefined and undervalued focus within the store.

Stock reduction is an important part of the operations of the store, and refers to the process of deploying new stock on shelves and registering that stock as available to customers in the store systems. This task is targeted for completion at 8 am every day, and this forms the primary KPI for that department. While this time was achieved on the morning the researcher accompanied stock control (beginning at 5 am), it was commented that it is usually 'an impossible task'. This is particularly true at times of high volume. This is largely a product of another bullwhip effect, where data errors that inform delivery from the warehouse impact on operations in store. In addition, connectivity issues for PDAs - a function of bandwidth and coverage issues in store - create delays in data processing and retrieval also affect this task. There are over 10,000 lines in store at any time, so this is a data and task intensive role. Prices are downloaded weekly from the central office, and this system provides labels that must be printed and then verified through the use of the PDA handset. This is used to create Shelf Edge Labels (SELs) which are critical for stock check and online order fulfilment. Changeover is the most intensive part of the role; a huge job, involving label production for legal sales of both store reductions and increases in price for goods coming off promotion. This must be done by $7 \mathrm{am}$ on the day of sales. The night crew has two people dedicated to this task, but the main means of communication between the night and day shifts is a communications book and a weekly meeting at 7 am on a Tuesday. Again, this is an example of highly controlled, formal work incorporating loosely disciplined regimes of governance that are ill suited to the task resulting in data errors that effect formal execution.

Equipment issues are also seen in the front-end operation, where the processes of working on checkout terminals were described as: monotonous, automated, datadriven, repetitive and characterised by a rigidity of movement, function and action. 
The haptic interface is identical across terminals rather than being optimally configured for each worker. The electrical department shares the systems overload issue; it has three web-portal based records systems, all accessible through an antiquated desktop PC with no Wi-Fi connection. If there is no internet connection available, there is no electrical retail. All systems are web based, and interruptions in connectivity are frequent and problematic. Getting service back involves unplugging and resetting, as there no technical assistance available. The data-intensive environment itself stands in contrast to the equipment and practices of interfacing and using data in the store.

\section{Conclusion}

Over the last thirty years, retail has become ever more dependent on big data systems such as ERP, SCM and CRM to function. These systems are seen as vital for gaining insight to guide decision-making, create efficiencies, improve customer service, reduce risk and costs, and manage the work of staff. Key to such operational improvements is labour being monitored extensively and modulated in new ways through the use of big data systems. Our research sought to answer three questions with respect the use of such systems: (1) how is the governance of labour shifting in modern retail? (2) how does this work in practice? (3) what are the effects on workers?

From our analysis, it is clear that big data systems are being extensively deployed across various forms of retail work and they are having a significant impact on operations. This is because they work to create a condition in which the spaces (e.g. store, warehouse, logistics) and practices (e.g. management, sales, deliveries, communications) of retail are pervasively mediated through computation, and introduce a regime of control that shifts the management of labour from surveillance and discipline to capture and modulation. This is a significant shift, with the management of work increasingly being automated, mediated, monitored and regulated by code and data that saturates all tasks and sites of labour. Even where managers are still directly involved, their work is directed by a series of auto-generated KPIs and data-reactive work processes.

Yet, as we have detailed through our empirical study this regime of control is highly precarious and fallible, open to vertical and horizontal fissures that disrupt the various operations vital to the functioning of a store. For example, tasks can become datasatisfying rather than operations- or customer-focused; symbolic labour vital to customer satisfaction is largely ignored; and systemic system and equipment failures continually disrupt operations. As a consequence, retail work involves a continual movement between a regime of control that seeks to regulate and harnesses formal labour and automation, and a disciplinary regime that deals with the symbolic, interactive labour that workers perform and acts as a reserve mode of governmentality when control fails (see also Newsome et al., 2013: 7-8). Consequently, rather than the retail environment becoming inherently more nimble, flexible, innovative and smart in how it is organised and operates, as suggested by operations research and the big data industry (e.g. Manyika et al., 2011), big data systems produce a number of effects that hinder effective operation and require staff to find workaround solutions and management to revert to disciplinary regimes. Indeed, despite the dependence and ubiquity of big data in the store, the actual equipment that interfaces with the various store systems actively work to prevent formal labour being more efficient. One manager remarked that the effect of this is that 'the environment that has been created by the data flows also makes it too fast to think... there is no time to reflect on what works and what might work, as the KPIs always have to be met and decisions and planning are data, rather than knowledge, based.' In other words, while the store is a big data environment, the tools for working in the store do not match the data-intensive functioning of the store,

Moreover, the use of these systems mean that customer satisfaction is also being delegated to big data and algorithmic processing in order to understand 'customer behaviour' to drive sales and improve customer experience. The implication of such measures 
is that getting to know customers is no longer about face-to-face interactions and symbolic labour and more about efficiency in formal work (Sallaz, 2010). Moreover, the reliance on big data systems to manage customers means workers experiencing less chance to develop or exercise soft skills (or emotional labour) with customers (Barocas and Levy, 2016). Yet, face-to-face interactions do not disappear; they are still critical in the presentation of the service aspect of a retail store but without mechanisms to capture and reward this labour, this work is undervalued and only partially visible.

In turn these disjunctions create worker dissatisfaction in a number of ways, such as symbolic labour being undervalued; coping with the different (or non-existent) reward and punishment mechanisms, and the oscillation and mismatch between control and disciplinary regimes and the paradoxical, contradictory and confusing situations that arise; dealing with the stress of poor functioning systems and the negative consequences with respect to customer interaction and satisfaction; and experiencing alienation with respect to the opaque systems that perform as an algocracy. This is compounded by a lack of understanding on the part of employees about how their particular activities or actions feed into the operational parameters of the organisation as a whole, and about how individual actions that are digitally mediated or facilitated contribute to the organisation. In particular, there was a sense amongst workers that they operate as cogs within a machine rather than providing a service for customers. Such disengagement resonates with the observations of Danaher (2016a) and Sennett (1998: 109) of a lack of satisfaction in work as the worker is divorced from the motivation and reasoning for work.

Our research thus highlights that the retail industry has some way to go to effectively embed big data systems into their operations that maximise operational efficiency while enhancing worker management and experience and customer satisfaction. In fact, the horizontal and vertical fissures we identified suggest that such an alignment will be extremely difficult to achieve due to the inherent contradictions of seeking to maximise productivity and profit at the same time as maximising worker and customer satisfaction. Rather than trying to square this circle through another round of technological solutionism (Morozov, 2013b), our sense is that it requires an organisational approach that considers the use of technology in context, maps outs unanticipated consequences, and considers novel solutions that take advantage of the benefits of computation and big data, but does not lose sight of the fact that retail is a high personable activity. Retail relies on large numbers of customer-facing workers, and even larger numbers of customers, and brand image and reputation are extremely important, not simply efficiency and price.

More research is needed, we believe, to map out the uses and consequences of big data on business operations and labour. This should take at least four forms. First, there needs to be an extension of our work within the retail sector and to chart in detail the ways in which big data systems are being deployed and the horizontal and vertical fissures that disrupt their intended disruptive innovation. Second, this research needs to become comparative with regards to type of retail sector, scale of operations, and location. For example, in retail that is predominately conducted online, the parameters of customer satisfaction are somewhat different, with only the customer-relations department being predominately customer facing. Further, the scales of economy for deployment will vary across businesses and thus affect workplaces differentially. Moreover, there are likely to be variation in how systems are configured and used across jurisdictions depending on local workplace culture, influence of unions, labour laws, and other regulations. Third, how big data systems are reconfiguring the management and practices of labour in other sectors requires analysis and comparison. It is likely that horizontal and vertical fissures will have emerged in these contexts, but may have different forms and consequences. Fourth, more attention needs to be paid to the formulation of normative interventions that consider the ethics, politics and praxes of big data systems with respect to workplace governmentality and labour and to forwarding alternative ethos, ethics of care, and instrumental arrangements that have positive worker and customer effects while still benefitting from the use of computation and big data (Laaser and Bolton, 2017). In each case, understanding the 
workplace changes underway will benefit from ethnographic insights built on firsthand observation and participation in the functioning of work as it unfolds in practice rather than as intended. Without such research and re-envisioning it seems that many workplaces will be far from smart places to work.

\section{Acknowledgements}

The research for this paper was provided by a European Research Council Advanced Investigator Award, 'The Programmable City' (ERC-2012-AdG-323636).

\section{References}

Agre, P. (1994), 'Surveillance and Capture: Two Models of Privacy', Information Society 10, 2, 101-127.

Andrejevic, M. (2014), 'The big Data Divide', International Journal of Communication 8, 1673-1689.

Aneesh, A. (2006), Virtual Migration (Durham, UK: Duke University Press).

Ball, K. (2010), 'Workplace Surveillance: An Overview', Labour History 51, 1, 87-106.

Barocas, S. and Levy K. (2016), What Customer Data Collection Could Mean for Workers, Harvard Business Review, https://hbr.org/2016/08/the-unintended-consequence-of-customer-data-collection (accessed 03 March 2017).

Braun, B.P. (2014), 'A new Urban Dispositif? Governing Life in an age of Climate Change', Environment and Planning D: Society and Space 32, 49-64.

Carter, B., A. Danford, D. Howcroft, H. Richardson, A. Smith and P. Taylor (2011), "All They Lack is a Chain': Lean and the new Performance Management in the British Civil Service', New Technology, Work and Employment 26, 83-97.

Chopra, S., and P. Meindl (2012), Supply chain management: strategy, planning, and operations (5th ed.). London: Pearson Prentice-Hall.

Correll, S.J., E.L. Kelly, L.T. O'Connor and J.C. Williams (2014), 'Redesigning, Redefining Work', Work and Occupations 41, 1, 3-17.

Danaher, J. (2016a). Will Life be Worth Living in a World Without Work? Technological Unemployment and the Meaning of Life. Science and engineering ethics, 23, 1, 1-24.

Danaher, J. (2016b), 'The Threat of Algocracy: Reality, Resistance and Accommodation', Philosophy and Technology 29, 3, 245-268.

Dash, A. (2014). "What is Public?" Medium, July 24th, 2014, https://medium.com/message/ f33b16d780f9 (accessed 13 April 2017).

Deleuze, G. (1992). Postscript on the Societies of Control. October, 59, 3-7.

Deleuze, G. (1995), Negotiations, 1972-1990. (New York: Columbia University Press).

Dery, K., R. Hall and N. Wailes (2006), 'ERPs as Technologies-in-Practice: Social Construction, Materiality and the Role of Organisational Factors', New Technology, Work and Employment 21, 3, 229-241.

Dodge, M. and R. Kitchin (2007), 'The Automatic Management of Drivers and Driving Spaces', Geoforum 38, 2, 264-275.

Ehrenreich, B. (2010), Nickel and Dimed: On (not) Getting by in America (New York: Macmillan).

Estlund, D. (1993), 'Making Truth Safe for Democracy' in Copp, D., Hampton, J. and Roemer, J. (eds) The Idea of Democracy. (Cambridge: Cambridge University Press).

Fairclough, N. (1995), Critical Discourse Analysis. (Boston: Addison Wesley).

Floridi, L. (2014), 'Technological Unemployment, Leisure Occupation, and the Human Project', Philosophy and Technology 27, 2, 143-147.

Foucault, M. (1979), Discipline and Punish: The Birth of the Prison. (New York: Penguin).

Fuller, M. and A. Goffey (2012), Evil Media. (Cambridge, MA: MIT Press).

Gilbreth, F.B. and L.M. Gilbreth (1917), Applied Motion Study. (New York: Sturgis \& Walton Company).

Gregg, M. (2016), The Athleticism of Accomplishment, in J. Wajcman, and N. Dodd (eds), The Sociology of Speed: Digital, Organizational, and Social Temporalities (Oxford, UK: University Press), pp. 102-116.

Head, S. (2014), "Worse Than Wal-Mart: Amazon's Sick Brutality and Secret History of Ruthlessly Intimidating Workers." Salon. http://www.salon.com/2014/02/23/worse_than_wal_mart_ amazons_sick_brutality_and_secret_history_of_ruthlessly_intimidating_workers/(accessed 12 April 2017). 
Hochschild, A.R. (1985), The Managed Heart: Commercialization of Human Feeling. (Berkeley: University of California Press).

Keynes, J.M. (1936), The General Theory of Employment, Money and Interest (London: Macmillan).

Kitchin, R. (2014), The Data Revolution: Big Data, Open Data, Data Infrastructures and Their Consequences. (London: Sage).

Kitchin, R. and M. Dodge (2011), Code/Space: Software and Everyday Life. (Cambridge, MA: MIT Press).

Laaser, K. and S. Bolton (2017), 'Ethics of Care and co-Worker Relationships in UK Banks', New Technology, Work and Employment 32, 213-227.

Lazzarato, M. (1996), Immaterial Labour, in M. Hardt, and P. Virno (eds), Radical Thought in Italy: A Potential Politics (Minneapolis and London: University of Minnesota Press), pp. 133-147.

Leidner, R. (1993), Fast Food, Fast Talk: Service Work and the Routinization of Everyday Life. (Berkeley: University of California Press).

Manyika, J., Chiu M., , Brown B., Bughin J., Dobbs R., Roxburgh C. and Hung Byers A. (2011), Big Data: The Next Frontier for Innovation, Competition, and Productivity (San Francisco, CA: McKinsey Global Institute).

McClelland, M. (2012), "I Was a Warehouse Wage Slave" Mother Jones, http:/ / www.motherjones. $\mathrm{com} /$ politics/2012/02/mac-mcclelland-free-online-shipping-warehouses-labor (accessed 12 April 2017).

Mittelstadt, B.D. and L. Floridi (2016), 'The Ethics of big Data: Current and Foreseeable Issues in Biomedical Contexts', Science and Engineering Ethics, 22, 303-341

Morozov, E. (2013a), 'The Real Privacy Problem', Technology Review 116, 6, 32-43.

Morozov, E. (2013b), To Save Everything, Click Here: Technology, Solutionism, and the Urge to Fix Problems That Don't Exist. (New York: Allen Lane).

Newsome, K., P. Thompson and J. Commander (2013), 'You Monitor Performance at Every Hour: Labour and the Management of Performance in the Supermarket Supply Chain', New Technology, Work and Employment 28, 1, 1-15.

Roethlisberger, F.J. and Dickson W.J. (2003 [1939]). Management and the Worker, Vol. 5. (New York: Psychology Press).

Rossiter, N. (2014), 'Logistical Worlds', Cultural Studies Review 20, 1, 53-62.

Sallaz, J.J. (2010), 'Service Labour and Symbolic Power: On Putting Bourdieu to Work', Work and Occupations 37, 3, 295-319.

Savat, D. (2012), Uncoding the Digital: Technology, Subjectivity and Action in the Control Society. (New York: Springer).

Sennett, R. (1998), The Corrosion of Character: The Personal Consequences of Work in the New Capitalism. (New York: W.W. Norton and Company).

Smith, V. (2012), "'You Get the Economy You Choose" The Political and Social Construction of the New Economy', Work and Occupations 39, 2, 148-156.

Stiegler, B. (2010), Technics and Time, 3: Cinematic Time and the Question of Malaise. (Stanford: Stanford University Press).

Taylor, F.W. (1903), Shop Management (New York, NY: American Society of Mechanical Engineers), OCLC 2365572. Project Gutenberg

Toth, P. (2015), Vehicle Routing: Problems, Methods, and Applications, 2nd edn. (Cambridge: Cambridge University Press).

Wang, Y., V. Sanchez Rodrigues and L. Evans (2015), 'The use of ICT in Road Freight Transport for $\mathrm{CO}^{2}$ Reduction-An Exploratory Study of UK's Grocery Retail Industry', The International Journal of Logistics Management 26, 1, 2-29.

Wygonik, E., A. Bassok, A. Goodchild, E. McCormack and D. Carlson (2015), 'Smart Growth and Goods Movement: Emerging Research Agendas', Journal of Urbanism 8, 115-132. 